\title{
Comparative Analysis of Single-Phase Grid-Tied PV Systems with Single and Double Power Conversion Stages
}

\author{
L. P. Sampaio, S. A. O. Silva and M. Miranda \\ Department of Electrical Engineering \\ Federal University of Technology - UTFPR-CP, Campus of Cornélio Procópio \\ Av. Alberto Carazzai, 1640. CEP. 86.300-000 Cornélio Procópio - PR - Brazil \\ Phone/Fax number:+0055 43 35204000, e-mail: sampaio@utfpr.edu.br $\underline{\text { augus@utfpr.edu.br }}$
}

\begin{abstract}
This paper presents a comparative analysis of two single-phase grid-tied photovoltaic (PV) systems. The first is deployed employing a single-stage power conversion, while the second a double-stage power conversion is used. In the singlestage PV system topology the impedance source inverter (ZSI) is used to perform the maximum power point tracking (MPPT), as well as the control of the active current injected into the grid. On the other hand, in the double-stage PV system a dc-dc boost converter (BC) performs the MPPT, whereas a voltage source inverter (VSI) controls the amount of energy injected into the grid. In both aforementioned PV systems, Perturb and Observe (P\&O) based algorithm is employed to perform the MPPT. The comparative analysis takes into account the following aspects: i. converter efficiency; ii MPPT efficiency; iii total harmonic distortion of the grid-tied inverter current; and iv. number of electrical and electronic devices needed to implement the PV systems. Furthermore, the ZSI and BC+VSI modelling and the procedures used to design the controller gains are also presented. Finally, by means of computational simulations, the performance and functionality of the ZSI and BC+VSI PV systems are evaluated.
\end{abstract}

\section{Key words}

Impedance Source Inverter, Voltage Source Inverter, Photovoltaic Systems, Perturb and Observe.

\section{Introduction}

The interest in solar energy for supplementing energy generation has been increased, especially due to environmental concerns, as well as the fast increase of electricity demand and possible shortage of some energy sources based on fossil fuels and mineral coal. Moreover, in the last years the costs of PV panels have significantly reduced, which makes this green power source more attractive [1].

Usually, the PV systems are deployed using topologies with double-stage power conversion. The first power conversion stage is implemented by means of dc-dc stepup converter to perform the maximum power point tracking (MPPT), whereas a voltage source inverter (VSI) is used in the second power stage controlling the amount of energy injected into the grid [2]. Although, PV systems employing double-stage power conversion have been widely employed, some disadvantages can be observed, such as lower efficiency, lower reliability, higher cost due to the dcdc converter and larger size [3],[4].

In order to overcome the aforementioned disadvantages, the impedance source inverter (ZSI) has been proposed [5],[6]. The single-stage ZSI topology has an impedance network that consists of two inductors and two capacitors connected in $\mathrm{Z}$ shape. This impedance allows a switching state called "shoot-through" state (ST), which is prohibited in VSI topologies.

Therefore, taken into account the new switching state, the ZSI output voltage can be higher or lower than the input voltage. As the ZSI can handle the ST state, its reliability is greatly enhanced. Furthermore, the costs can be minimized because less power switches are employed, as well as the passive elements can be designed in order to reduce the converter volume. As a result, the efficiency is improved, once the boosting, the MPPT and the active current injection into the grid are performed using a single-stage power conversion [7].

Thus, this paper proposes a comparative analysis of two single-phase grid-tied PV systems, where the ZSI is employed as single-stage power conversion topology to perform the MPPT, as well as the control of the active current injected into the grid. On the order hand, the double-stage power conversion is deployed using the dc-dc boost converter (BC) to track the MPP, whereas the VSI controls the amount of energy to be injected into the grid. The maximum power of the PV array is tracked employing the Perturb and Observe ( $\mathrm{P} \& \mathrm{O})$ MPPT based algorithm. Consequently, the comparative analysis takes into account the following aspects: i. converter efficiency; ii MPPT efficiency; iii total harmonic distortion of the grid-tied inverter current; and iv. number of electrical and electronic devices needed to implement the systems. 


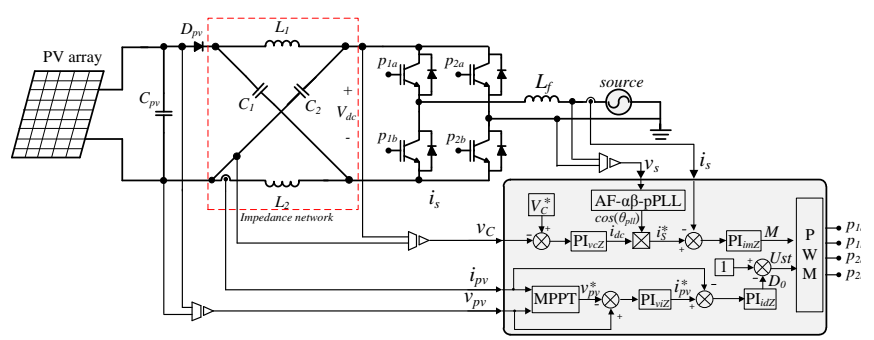

(a)

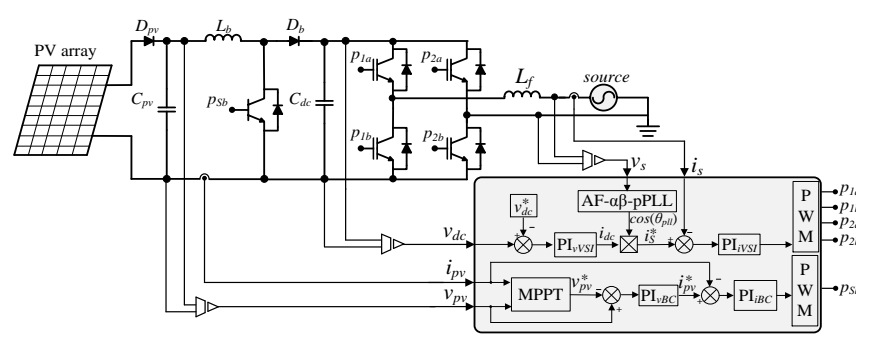

(b)

Fig.1. Diagram block of two single-phase grid-tied PV systems: (a) ZSI topology; (b) BC+VSI topology

\section{Single-Phase Grid-Tied PV Systems}

The power circuit of the two single-phase grid-tied PV systems studied in this work as well as, the complete control diagram, are shown in Fig. 1. The single-stage power conversion deployed with ZSI is shown in Fig. 1 (a), while the double-stage PV system employed with $\mathrm{BC}+\mathrm{VSI}$ is presented in Fig. 1 (b). The PV panel adopted in this work is the Sunmodule Plus SW 245 (SolarWorld). The complete array is formed by 4 series connected panels, providing maximum PV output power of $960 \mathrm{~W}$ in standard test conditions (STC).

In the following sub-sections are described the modelling and control diagram of the ZSI and BC+VSI topologies, as well as the P\&O-based MPPT algorithm and the phaselocked-loop (PLL) adopted in this work.

\section{A. Control strategy applied to ZSI topology}

The DC side of the ZSI is modulated employing the simple boost control (SBC) [8]. Usually, a capacitor voltage inner loop is used to control the input current in order to handle the zero in the right-half plane (RHP). The RHP zero appears in the traditional voltage loop control, in order to determine the control-to-output transfer function $\left(v_{p v} / d_{0}\right)$ [9]. The parameter $d_{0}$ is used to control the ZSI boost.

Therefore, in order to reduce the effect of the zero in the RHP, in this paper is adopted a multi-loop control, such that the PV voltage transfer function is $v_{p v} / i_{p v}$, and the PV current transfer function is $i_{p v} / d_{0}$.

Once the multi-loop control provides high dynamics and stability to the system, this control methodology is adopted for the ZSI DC-bus side, as shown in Fig. 2 (a). Thus, the inner input current control loop is used to control the PV system current $\left(i_{p v}\right)$, which is considered equal to the inductance current of the impedance network $\left(i_{L}\right)$. The outer voltage control loop aims to regulate the PV system voltage $\left(v_{p v}\right)$ according with the voltage reference $\left(v_{p v}^{*}\right)$ obtained by means of the P\&O MPPT algorithm. The gains of the PI controllers, $k_{P v d c Z S I}$ and $k_{I v d c Z S I}$ are the respective proportional and integral voltage controller gains and $k_{\text {PidcZSI }}$ and $k_{\text {IidcZSI }}$ are the respective proportional and integral current controller gains. The parameter $R_{m p p}=$ $V_{P V \_m p p} / I_{P V \_m p p}$ represents the small-signal differential resistance of the PV generator at MPP [10]. Additionally, $L$ and $R_{L}$ represent the inductance and resistance of the impedance network, respectively.
The AC side of ZSI is controlled taking into account the available power in the PV array, in which the amplitude of the active current $\left(i_{d c}\right)$ is obtained by means of the capacitor voltage $\left(v_{C}\right)$ regulation, with the purpose to determine the current reference $\left(i_{s}^{*}=i_{d c} \cos \theta_{p l l}\right)$, as shown in the block diagram of Fig. 2 (b). The utility phaseangle $\left(\theta_{p l l}\right)$ is estimated by the PLL system [11]. Thus, the AC current control loop is employed to perform the sinusoidal current tracking with unity power factor. The parameters $L_{f}$ and $R_{L f}$ represent the inductance and resistance of the AC L-filter, $K_{P W M}$ represents the static gain of the PWM converter (peak value of the PWM triangular carrier), and $m$ is the modulation index used to determine the AC output voltage of the ZSI. Both the PI voltage controller gains, $k_{P v Z S I}$ and $k_{I v Z S I}$, and the PI ACcurrent controller gains $k_{P i Z S I}$ and $k_{I i Z S I}$, that are shown in Fig. 2 (b), are designed by means of methodologies based on frequency response, as proposed in [12].

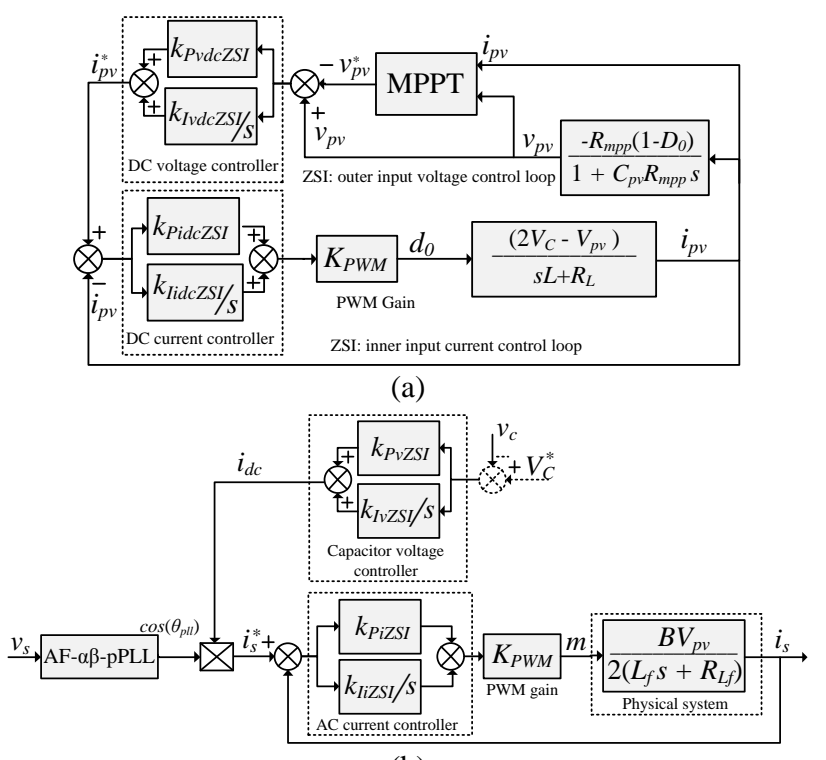

(b)

Fig. 2. ZSI system diagrams: (a) Block diagram of the multi-loop control applied to the DC side of ZSI topology; (b) Block diagram of the ZSI AC current control loop and ZSI capacitor voltage controller

\section{B. Control strategy applied to BC+VSI topology}

Similar to the control applied on the DC side of ZSI, a multi-loop control is also applied to the $\mathrm{BC}$ of the doublestage power conversion topology, in order to control the PV system voltage $\left(v_{p v}\right)$ and current $\left(i_{p v}\right)$, as shown in the block diagram of Fig. 3 (a). The two control loops are controlled by means of PI controllers, such that $k_{P v B C}$ and $k_{I v B C}$ are the respective proportional and integral voltage 
controller gains (outer loop), and $k_{P i B C}$ and $k_{I i B C}$ are the respective proportional and integral current controller gains (inner loop). In addition, $L_{b}$ and $R_{L b}$ represent the inductance and resistance of the boost inductor, respectively, and $C_{p v}$ represents the capacitance of the input filtering capacitor as shown in Fig. 1 (b).

The amount of energy extracted from the PV array is injected into the utility grid employing the VSI, in which the active current is controlled by means of the AC current control loop, as shown in Fig. 3 (b). In this control loop $L_{f}$ and $R_{L f}$ represent the inductance and resistance of the L-filter connected to the grid. The PI controller applied to the DC-bus voltage controller is also presented in Fig. 3 (b) and its modelling is detailed in [12]. Both the DC-bus PI controller gains, $k_{P v V S I}$ and $k_{I v V S I}$, and the PI AC-current controller gains $k_{P i V S I}$ and $k_{I i V S I}$, which are shown in Fig. 3 (b), are designed by means of methodologies based on frequency response, as proposed in [12].

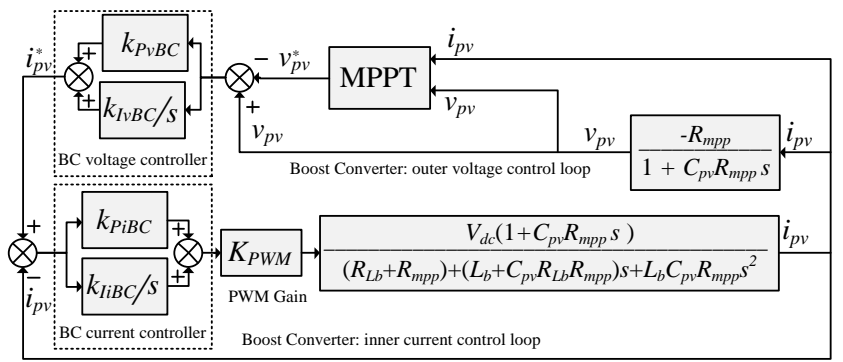

(a)

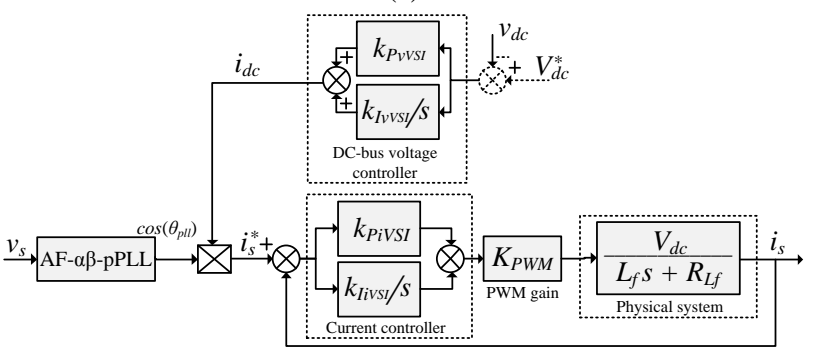

(b)

Fig. 3. BC+VSI system diagrams: (a) Block diagram of the multiloop control applied to the DC-DC boost converter; (b) Block diagram of the VSI current control loop and DC-bus VSI voltage controller

Therefore, the active current injected into the grid is given by $i_{s}^{*}=i_{d c} \cos \theta_{p l l}$, such that $i_{d c}$ is obtained from the DCbus voltage controller, which is determined according with the amount of extracted energy from the PV array and, the $\theta_{p l l}$ is the utility phase-angle estimated by the PLL system.

\section{Phase-locked loop system}

Fig. 4 presents the single-phase PLL algorithm used in the both PV systems, where its description is detailed in [11]. In the adopted PLL, a non-autonomous adaptive filter (AF) operates in conjunction with the $\alpha \beta$-pPLL in order to improve the PLL performance when the utility voltage is under disturbances, e.g., voltage harmonics, voltage sags/swells, phase-angle jumps and frequency variations. Moreover, the complete procedures used to determine the proportional $\left(k_{P p l l}\right)$ and integral $\left(k_{I p l l}\right)$ controller gains of the PLL are also presented in [11].

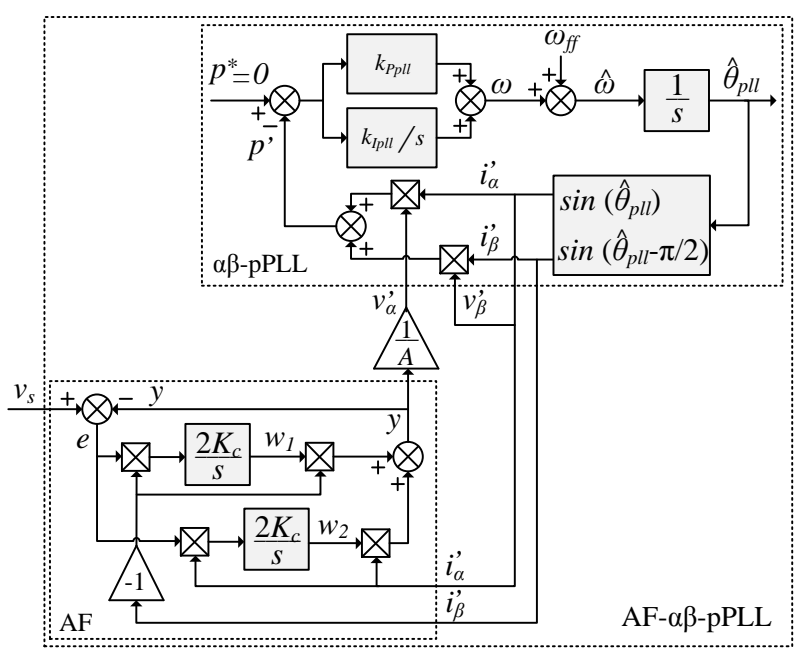

Fig. 4. Block diagram of Single-phase AF- $\alpha \beta-$ pPLL scheme

\section{P\&O-based MPPT technique description}

In order to extract the maximum power from the PV array, the P\&O MPPT algorithm was implemented as shown in Fig. 5. The MPPT algorithm operates by incrementing or decrementing the voltage reference $\left(v_{p v}^{*}\right)$, in order to extract the maximum power from the PV array [13]. The voltage reference $\left(v_{p v}^{*}\right)$ is employed in both ZSI and $\mathrm{BC}+\mathrm{VSI}$ outer voltage control loops.

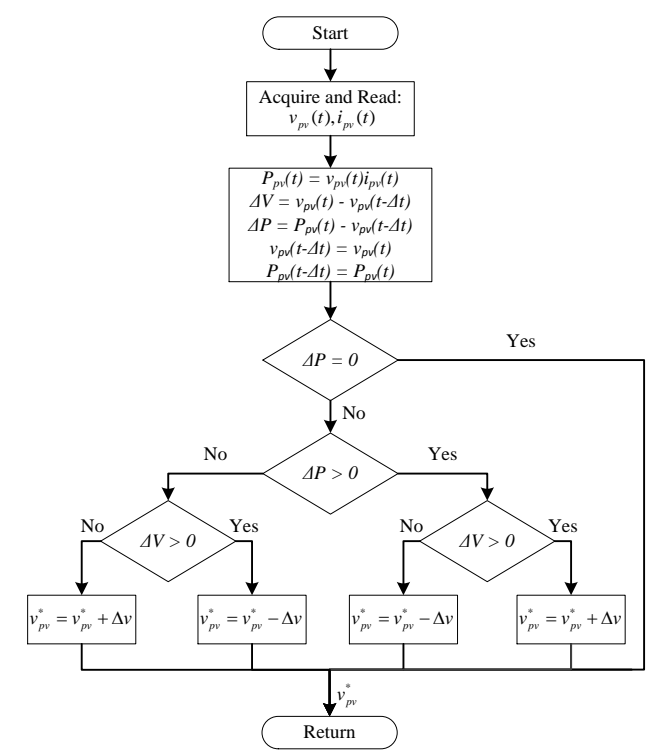

Fig. 5. Block diagram of P\&O MPPT algorithm

\section{Simulation Results}

The ZSI and BC+VSI single-phase grid-tied PV systems were simulated using the software MATLAB \& Simulink. Similar design specifications, such as phase margin and crossover frequency, were used to obtain the controller gains adopted in the voltage and current control loops. In addition, the same criteria were adopted to design the electrical and electronic devices. Table I presents the parameters of the PV module employed in this paper. Table II summarizes the common parameters used for both PV systems, while Table III and IV show the parameters for the ZSI and BC+VSI systems, respectively. 
Table I. - Standard test conditions (STC) of the SolarWorld sunmodule plus SW 245 PV array

\begin{tabular}{|c|c|}
\hline Maximum PV power & $P_{\max }=245 \mathrm{~W}$ \\
\hline MPP voltage & $V_{m p p}=30.8 \mathrm{~V}$ \\
\hline MPP current & $I_{m p p}=7.96 \mathrm{~A}$ \\
\hline Open circuit voltage & $V_{o c}=37.5 \mathrm{~V}$ \\
\hline Short-circuit current & $I_{s c}=8.49 \mathrm{~A}$ \\
\hline
\end{tabular}

Table II. - Common parameters used ZSI and BC+VSI topologies.

\begin{tabular}{|c|c|}
\hline Nominal utility rms voltage & $V_{s}=127 \mathrm{~V}$ \\
\hline Nominal utility frequency & $f_{s}=60 \mathrm{~Hz}$ \\
\hline $\begin{array}{c}\text { Switching frequencies of the PWM } \\
\text { converters (ZSI and BC+VSI) }\end{array}$ & $f_{s w}=20 \mathrm{kHz}$ \\
\hline Nominal power of the PV systems & $P_{s}=960 \mathrm{~W}$ \\
\hline Sampling frequency & $f=60 \mathrm{kHz}$ \\
\hline PWM gain & $K P W M=1$ \\
\hline PV array filtering capacitance & $C_{p v}=1000 \mu \mathrm{F}$ \\
\hline PV array differential resistance (STC) & $R_{m p p}=7.74 \Omega$ \\
\hline PLL PI controller gains & $\begin{array}{c}k_{P p l l}=424.3 ; \\
k_{I p l l}=32234\end{array}$ \\
\hline $\begin{array}{c}\text { Adaptive filter step size parameter (AF- } \\
\text { pPLL) }\end{array}$ & $\mu=0.007$ \\
\hline Sampling time (AF-pPLL) & $\mathrm{T}=16.66 \mu \mathrm{s}$ \\
\hline Adaptive filter gain (AF-pPLL) & $K_{c}=420$ \\
\hline $\begin{array}{c}\text { Cut off frequency (SRF Controller) } \\
\text { (2 }{ }^{\text {nd }} \text { order LPF Butterworth filter) }\end{array}$ & $f_{c}=30 \mathrm{~Hz}$ \\
\hline P\&O voltage step size & $\Delta v=0.8 \mathrm{~V}$ \\
\hline P\&O iteration time & $T_{M P P T}=1.25 \mathrm{~ms}$ \\
\hline
\end{tabular}

Table III. - Parameters used in the PV system with ZSI.

\begin{tabular}{|c|c|}
\hline ZSI AC inductive filter & $L_{f}=1.5 \mathrm{mH}$ \\
\hline ZSI AC inductive filter resistance & $R_{L f}=0.18 \Omega$ \\
\hline Impedance network capacitor voltage & $V_{C}=230 \mathrm{~V}$ \\
\hline Impedance network capacitances & $C_{1}=C_{2}=1500 \mu \mathrm{F}$ \\
\hline impedance network inductances & $L_{1}=L_{2}=L=4.6 \mathrm{mH}$ \\
\hline Resistance of the ZSI inductor & $R_{L}=0.2 \Omega$ \\
\hline ZSI AC-current PI controller gains & $\begin{array}{c}k_{\text {PiVSI }}=0.258 \\
k_{\text {IiVSI }}=3020\end{array}$ \\
\hline $\begin{array}{l}\text { ZSI Capacitor voltage PI controller } \\
\text { gains }\end{array}$ & $\begin{array}{c}k_{P v V S I}=0.184 \\
k_{I v V S I}=51.9\end{array}$ \\
\hline ZSI DC voltage PI controller gains & $\begin{array}{c}k_{P v i B C}=0.517 \\
k_{I v i B C}=174\end{array}$ \\
\hline ZSI DC current PI controller gains & $\begin{array}{c}k_{P i i B C}=0.074 \\
k_{\text {IiiBC }}=273\end{array}$ \\
\hline
\end{tabular}

Table IV. - Parameters used in the PV system with BC+VSI.

\begin{tabular}{|c|c|}
\hline VSI Inductive filter & $L_{f}=1.5 \mathrm{mH}$ \\
\hline VSI Inductive filter resistance & $R_{L f}=0.18 \Omega$ \\
\hline VSI DC-bus voltage & $V_{d c}=230 \mathrm{~V}$ \\
\hline VSI DC-bus capacitor & $C_{d c}=2500 \mu \mathrm{F}$ \\
\hline Boost filtering inductance & $L_{b}=3.6 \mathrm{mH}$ \\
\hline Resistance of the boost inductor & $R_{L b}=0.18 \Omega$ \\
\hline VSI Current PI controller gains & $\begin{array}{c}k_{P i V S I}=0.18 ; \\
k_{I i V S I}=2210\end{array}$ \\
\hline VSI DC-bus PI controller gains & $\begin{array}{c}k_{P v V S I}=0.341 ; \\
k_{I v V S I}=25.7\end{array}$ \\
\hline Voltage PI boost controller gains & $\begin{array}{c}k_{P v B C}=0.385 ; \\
k_{I v B C}=93.8\end{array}$ \\
\hline Current PI boost controller gains & $\begin{array}{c}k_{P i B C}=0.0858 ; \\
k_{I i B C}=313\end{array}$ \\
\hline
\end{tabular}

Fig. 6 shows the PV array output power, voltage and current for both topologies considering step changes of solar irradiation. In order to compare both MPPT PV systems, it was taken into account the relationship between the amount of energy available and that drained from the PV array, well-known as tracking factor (TF). Thus, the TFs achieved to ZSI and VSI were around 98.5\% 94\%, respectively.
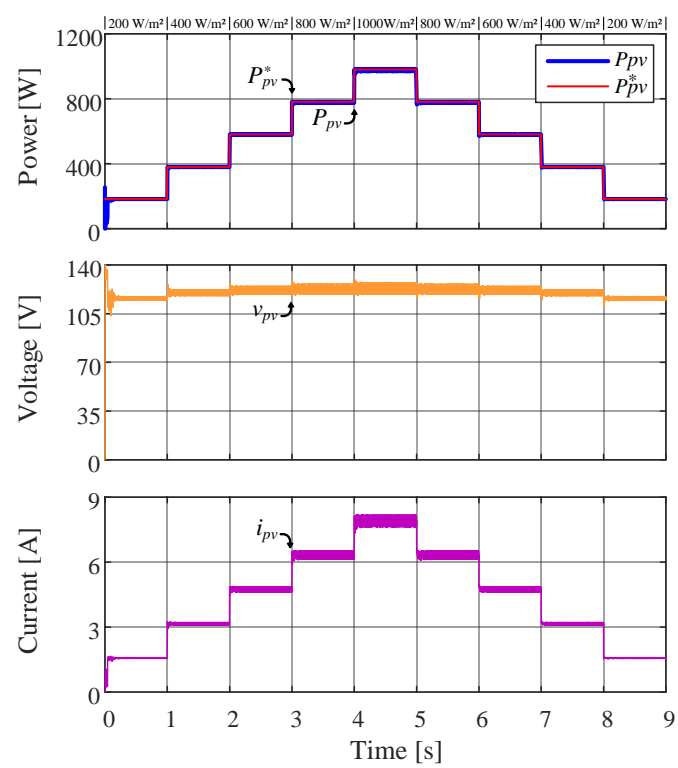

(a)
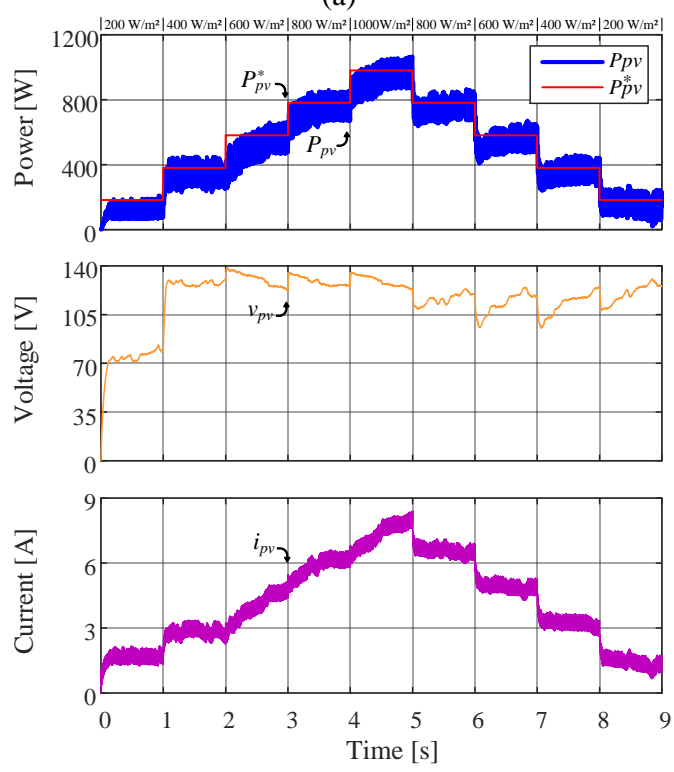

(b)

Fig. 6. PV array output power, voltage and current $\left(P_{p v}, v_{p v}, i_{p v}\right)$ for solar irradiation changes employing: (a) ZSI; (b) BC+VSI

As can be observed in Fig. 6, better performance was obtained to the multi-loop control applied to the PV array MPPT for the system with ZSI. After solar radiation step changes the ZSI PV array voltage achieved the settling time in around $0.1 \mathrm{~s}$, while $0.5 \mathrm{~s}$ was needed to $\mathrm{BC}+\mathrm{VSI}$ topology.

Fig. 7 shows the active energy extracted from the PV array being injected into the grid. As can be noted, the grid injected currents are sinusoidal and in opposite phase to the voltage grid. The current total harmonic distortion (THD) is equal to $2.5 \%$ for the ZSI PV system and $3.8 \%$ for the BC+VSI PV system topology. As can be noted, the current THDs of both PV structures are in accordance with the IEEE standard requirements [14]. 


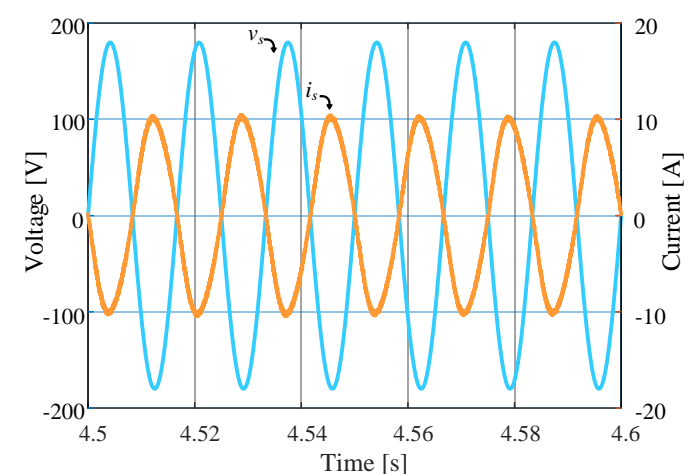

(a)

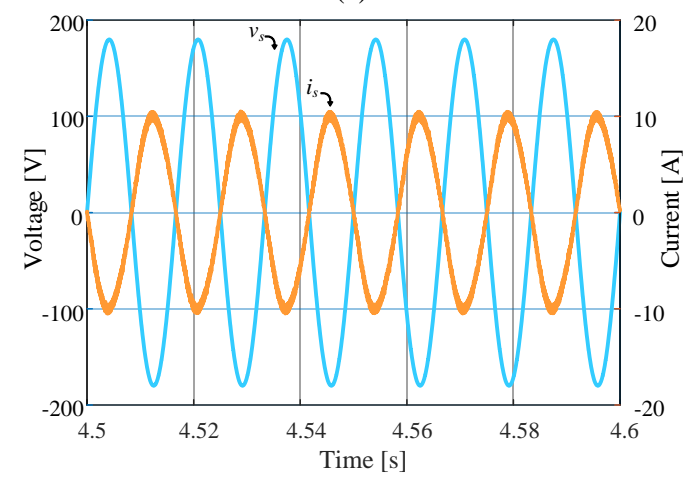

(b)

Fig. 7. PV systems performance. Utility voltage $v_{s}$ and current $i_{s}$ using (a) ZSI; (b) BC+VSI

Table V summarizes the comparative analysis involving the single and the double-stage power conversion PV systems, where were taken into account the number of electrical and electronic devices, the MPPT and PV system performances and the TDH of the grid injected currents.

Table V. - Main PV systems comparisons

\begin{tabular}{|c|c|c|}
\hline & $\overline{Z S I}$ & $\mathrm{BC}+\mathrm{VSI}$ \\
\hline \multicolumn{3}{|l|}{ Number of electrical and electronic devices } \\
\hline Inductors & 3 & 2 \\
\hline Capacitors & 3 & 2 \\
\hline Power Switches (IGBTs) & 4 & 5 \\
\hline Power Diodes & 1 & 2 \\
\hline MPPT Tracking Factor $(\%)$ & 98 & 94 \\
\hline MPPT Power convergence time (s) & 0.1 & 0.5 \\
\hline PV output power oscillation at STC (\%) & 2.1 & 16.3 \\
\hline THD of the inverter currents $i_{s}(\%)$ & 2.5 & 3.8 \\
\hline Peak voltage over the power switches (V) & 350 & 230 \\
\hline
\end{tabular}

Fig. 8 shows the efficiency of both PV systems taking into account the energy drained from the PV array. As can be observed, at STC, the efficiency of the BC+VSI is $1.5 \%$ higher than the ZSI topology. On the other hand, regarding the results of solar radiation step changes, the ZSI topology is more attractive, mainly, when the input power is less than $700 \mathrm{~W}$ ( $71 \%$ of the nominal input power). To perform the efficiency comparison, the manufacture parameters of the diode MUR860 and IGBT SKM50GB12T4, as well as the resistances of the inductors were considered.

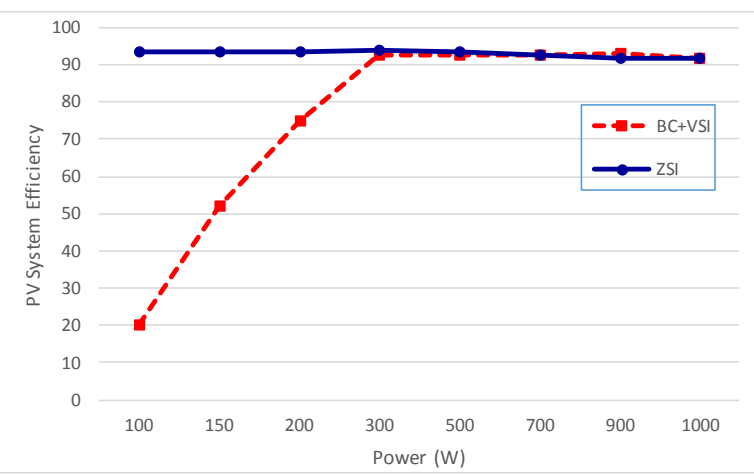

Fig. 8. Efficiency comparison of the ZSI and BC+VSI PV system topologies

\section{Conclusion}

This paper presented the main concepts of single-phase grid-tied PV systems employing ZSI and BC+VSI topologies. Moreover, a comparative analysis between the mentioned topologies including the controllers design and the P\&O MPPT technique was presented.

The ZSI topology presented several advantages when compared to BC+VSI topology, such that: superior tracking factor $(4.3 \%$ higher than the value obtained for the $\mathrm{BC}+\mathrm{VSI})$; the PV system multi-loop control has superior performance (fast dynamic response and less oscillations in steady-state); lower THD value in the gridtied inverter current $(2.5 \%$ for the ZSI versus $3.8 \%$ for the $\mathrm{BC}+\mathrm{ZSI})$. However, at STC the $\mathrm{BC}+\mathrm{VSI}$ presents $1.5 \%$ more efficiency than the ZSI topology. On the other hand, when habitual variations in the climate conditions (solar irradiation) is considered, the ZSI has shown more attractive, mainly, when the input power is lower than $71 \%$ of the nominal input power $\left(700 \mathrm{~W} / \mathrm{m}^{2}\right)$.

\section{References}

[1] C. S. da Silva, F. R. Motta and F. L. Tofoli, "Two-Stage Single-Phase Grid-Connected Photovoltaic System with Reduced Complexity", International Journal Electronics. vol. 98, no 6, pp. 753-767, June 2011.

[2] S. A. O. Silva, L. P. Sampaio, F. M. Oliveira and F. R. Durand, "Feed-forward DC-bus Control Loop Applied to a Single-Phase Grid-Connected PV System Operating with PSO-based MPPT Technique and Active Power-Line Conditioning", IET Renewable Energy [online], http://digital-library.theiet.org/content/journals/10.1049/ie t-rpg.2016.0120, accessed 12 December 2016.

[3] S. Jain and V. Agarwal, "A Single-Stage Grid Connected Inverter Topology for Solar PV Systems with Maximum Power Point Tracking", IEEE Transactions on Power Electronics, vol. 22, nº 5, pp. 1928-1940, Sep. 2007.

[4] Y. Li, P. Li, Y. Chen and D. Zhang, "Single-Stage ThreePhase Current-Source Inverter for Photovoltaic GridConnected System", in Proc. of EPE, 2014, pp. 1-9.

[5] O. Ellabban, H. Abu-Rub, "Z-Source Inverter: Topology Improvements Review", IEEE Industrial Electronics Magazine, vol. 10, no. 1, pp. 6-24, 2016.

[6] M. Adamowicz, R. Strzelecki, F. Z. Peng, J. Guzinski and H. A. Rub, "New type LCCT-Z-source inverters", in Proc. of EPE, 2011, pp. 1-10.

[7] M. Shen, A. Joseph, J. Wang, F. Z. Peng and D. J. Adams, "Comparison of Traditional Inverters and Z-Source 
Inverter for Fuel Cell Vehicles", IEEE Transactions on Power Electronics, vol. 22, n 4, pp. 1453-1463, July 2007.

[8] F. Z. Peng, M. Shen and Z. Qian, "Maximum Boost Control of the Z-Source Inverter", IEEE Transactions on Power Electronics, vol. 20, $\mathrm{n}^{\circ}$ 4, pp. 833-838, July 2005.

[9] C. J. Gajanayake, M. Vilathgamuwa and P. C. Loh, "Development of a Comprehensive Model and a Multiloop Controller for Z-Source Inverter DG Systems", IEEE Transactions on Industrial Electronics, vol. 54, $\mathrm{n}^{\circ} 4$, pp. 2352-3259, Aug. 2007.

[10] N. Femia, G. Petrone, G. Spagnuolo and M. Vitelli, "A Technique for Improving P\&O MPPT Performance of Double-Stage Grid-Connected Photovoltaic Systems", IEEE Transactions on Industrial Electronics, vol. 56, $\mathrm{n}^{\circ} 11$, pp. 4473-4482, Aug. 2009.

[11] V. D. Bacon, S. A. O. Silva, L. B. G. Campanhol and B. A. Angélico, "Analysis and Performance Evaluation of a Single-Phase Phase-Locked Loop Algorithm Using a NonAutonomous Adaptive Filter", IET Power Electronics, vol. 7, nº 8, pp. 2081-2092, 2014.
[12] B. A. Angélico, L. B. G. Campanhol and S. A. O. Silva, "Proportional-Integral/Proportional-Integral-Derivative Tuning Procedure of a Single-Phase Shunt Active Power Filter Using Bode Diagram", IET Power Electronics, vol. 7, no 10, pp. 2647-2659, 2014.

[13] M. A. G. Brito, L. P. Sampaio, L. Galotto Jr. and C. A. Canesin, "Evaluation of the main MPPT techniques for photovoltaic applications", IEEE Transactions on Industrial Electronics, vol. 60, $\mathrm{n}^{\circ}$ 3, pp. 1156-1167, 2013.

[14] IEEE Std. 929-2000: "IEEE recommended practice for utility interface of photovoltaic (PV) systems”, 2000. 